\title{
Global dendroclimatology in sight
}

from A. Barrie Pittock

Dendroclimatology, the systematic study of past climates using tree growth characteristics as proxy climate data, is a relatively young science. It is often confused with the much older and related science of dendrochronology, the dating of specimens by the use of tree-ring sequences. Dendroclimatology has only really developed as a science since the 1940 s, primarily as a result of the pioneering efforts of workers at the Laboratory of Tree-Ring Research at the University of Arizona. Elsewhere, the serious application of dendroclimatic methods has only begun in the last five years or so.

It was, therefore, encouraging to find at a recent workshop* attended by 56 scientists from 14 countries that dendroclimatology is making great strides. Greater global coverage was reported in contributions from Europe, Asia, South America, South Africa and Australia, as well as eastern North America and the Arctic. A striking departure from early research in the semi-arid southwest United States was the documentation of useful climatic sensitivity in trees from other than obviously stressed environments. This was particularly well demonstrated for Southern Hemisphere rain forest environments by La Marche and co-workers, for the eastern United States by Cook and for Europe by several groups (Schweingruber, Eckstein, Baillie, Pilcher, and see Hughes et al. 272, 606; 1978; Dunwiddie \& La Marche Naturer 286, 796; 1980; Garfinkel \& Brubaker Nature 286, 872; 1980). Major research groups (outside the western United States) now exist in several regions, including the United Kingdom, continental Europe and the eastern United States. Strong interest is also being shown in China (two workers were present at the meeting), Argentina, Australia and the Soviet Union. The Chinese plan to use treering data in regions such as the northwest where historical data are not abundant.

Climatologists were also present at the conference and this led to a stimulating interaction between the potential users of dendroclimatic data and the data producers. It was suggested that attempts should be made to reconstruct a wider range of climatic variables, alongside temperature, precipitation and surface

A. Barrie Pittock is in the Division of Atmospheric Physics, Commonwealth Scientific and Industrial Research Organization, Australia. *The Second International Workshop on Global Dendroclimatology was held at the Climatic Research Unit, the World Meteorological Organisations, the United Nations Enviroment Programme, the Scientific Affairs Division of NATO and the US National Science Foundation and was NATO and the US National Science Foundation and was (University of Fast Anglia) and J. P. Pilcher (Queen's University of Fast Anglia) and J. P. Pilcher (Queen

published in 1980 and a book in 198.
p. pressure and that sampling should be concentrated in regions which are climatologically important and/or where there are gaps in coverage from instrumental, historical or other proxy data. There is growing confidence that with some modification existing methods can extract useful climatic information from trees in many different parts of the world.

As dendroclimatology has expanded into new geographical areas over the last decade, techniques have been modified and refined. One example is the use of density as well as ring-width measurements for climate reconstructions. Density data have been used recently to reconstruct temperature data in Europe (Schweingruber et al. Tree-Ring Bulletin 38, 61; 1978). Although basically similar, the climate-growth response appears simpler for density than ring width (Parker Syesis $9,163 ; 1976)$. New techniques take into account that growth in a particular year is influenced by growth in prior years, that growth is a function of tree age and that the climate-growth response may change as trees age. A recent innovation has been the use of selective filter techniques in calculating the response and transfer functions.

Of special interest were plans for European climate reconstructions put forward by one of the global data base working groups. The plans gave high priority to building up a dense network of chronologies back to at least 1750 covering the whole of Europe. Using instrumental data from 1880 to the present for

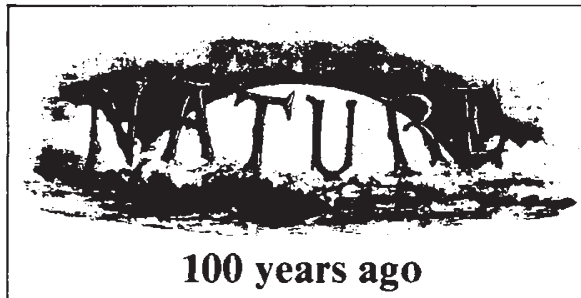

IT is stated that at the National Exhibition to be opened at Milan next year there will be a captive balloon, on the model of the one which was so successful in Paris in 1878. It will measure not less than 180 feet in circumference, 84 feet in height, and contain 15,000 cubic feet of gas. To it will be attached a safe and solid car, capable of containing seats for at least eight persons. A steam-engine is to regulate the ascent and descent, and it will rise to a height of about 900 feet, affording a splendid view of Milan and the plains of Lombardy. The balloon will be constructed at Milan, m. Henri Beudet, the well-known and experienced aëronaut, having been sent for to direct the work.

THE Boston Herald gives the following account of an American experiment made on September 2: — "A novel exhibition of powerful electric lights was made last evening calibration and earlier instrumental and historical data for verification, it should be possible to produce a detailed and continuous climate reconstruction from 1750. Because of the abundance of data for calibration and verification, this could prove the best continent-wide proxy climate data set in existence and Europe could become a test bed for refining dendroclimatic methods.

Five-hundred-year long chronologies are available already from living conifers in the Alps and at the northern tree-line and are expected from living oaks in Scotland, northern France and south-central Germany. These should allow the reconstructed record to extend back into the 15 th century, and extension back for 1,000 years at a reduced spatial density is possible (see Serre Tree-Ring Bulletin 38, 25 ; 1978). Abundant sub-fossil and archaeological material may be used to extend the chronologies still further. However, the use of such material poses methodological problems in matching series from dead wood with living trees, especially in a way which will not distort the low-frequency climatic information. Work on these problems is being actively pursued and its importance may be gauged from the potential development of severalthousand-year chronologies from various parts of the globe including Europe, North America and New Zealand. The application of densitometric and possibly isotopic methods may well overcome some of the more serious problems in using these long tree-ring chronologies.

in the vicinity of the Sea Foam-house, Nantucket Beach, and the display was witnessed by quite a crowd of interested spectators. The Northern Electric Light Company have erected three wooden towers, each 100 feet high, and mounted upon each of these a circular row of twelve electric lights of the Weston patent, each light being estimated at 2,500-candle power. As these towers are but 500 feet apart and in a triangle, it will be seen that the light of 90,000 candles was concentrated within a limited territory. The design of the exhibition was to afford a model of the plan contemplated for lighting cities from overhead in vast areas, the estimate being that four towers to a square mile of area, each mounting lights aggregating 90,000candle power, will suffice to flood the territory about with a light almost equal to midday. Last evening a motive power of thirty-six horses was used in generating the electricity from three Western machines, and the lights, with one single flicker, burned steadily and brilliantly all the evening. It is difficult to say whether the experiment proved anything or not. The claim put forward by the company is for an original plan of lighting cities and towns by grouping and elevating electric lights of any kind."

From Nature 22, 28 October, 593 \& 615, 1880. 